\title{
Motorists' Perceptions and Attitudes towards Ethanol Blended Fuel in Zimbabwe
}

\author{
Decide Mabumbo ${ }^{1}$ and Paramu Mafongoya ${ }^{2}$ \\ 1. Centre for the Advancement of Scholarship, University of Pretoria, Private Bag x20, Hatfield 0027, South Africa \\ 2. School of Agriculture, Earth and Environmental Sciences: University of KwaZulu-Natal, Pietermaritzburg 3209, South Africa
}

\begin{abstract}
Most developing and developed countries have enacted mandatory legislation for use of biofuels (bioethanol) in the transport sector. For most developing countries, the use of biofuels meant to increase energy security, save foreign currency, mitigate climate change, create jobs and rural development. However, motorists have limited knowledge on blended biofuels. This study seeks to investigate the level of awareness and prevailing attitudes of motorists in Zimbabwe where a mandatory ethanol blending policy was recently introduced. The study uses data derived from 200 respondents, to whom a questionnaire was administered. The major challenge faced by motorists is the lack of sufficient information on ethanol blends in general including how they can get their engines modified to take high ethanol blends. About $63.1 \%$ were not clear about the technical attributes of ethanol blended fuel especially as it relates to engine efficiency. Secondly, some motorists experienced a number of problems ranging from poor idling (36\%), lack of power (19.5\%) and difficulties with engine starting (16.5\%). Despite all these complaints, $54 \%$ of the respondents generally exhibit a positive attitude towards ethanol blended fuel and $60.3 \%$ said that they were keen to recommend blended fuel to other motorists. An appropriate institutional, legal and policy framework that supports massive awareness campaigns for use of bioethanol for the transport sector can go a long way to dispel negative perceptions associated with ethanol blends.
\end{abstract}

Key words: Biofuels, motorists, knowledge, attitude, perceptions.

\section{Introduction}

Governments all over the world have enacted mandatory legislation for use of biofuels (bio-ethanol) in the transport sector. For most developing countries, including Zimbabwe, the use of biofuels is meant to increase energy security, save foreign currency, climate change mitigation, create jobs and rural development [1]. However, despite legislative activity and wide spread media attention that biofuels have received in recent years, there is very little published work specifically exploring public perceptions and attitudes towards the rapidly expanding set of biofuel policies and technologies [2]. Limited research efforts have been dedicated to explore this phenomenon, particularly in Africa where the biofuels sector is still in its nascent stage.

Corresponding author: Paramu Mafongoya, Ph.D., research chair, research fields: integrated natural resources management, biofuels and agricultural development.
Most commercially available biofuels are first generation energy crops that are produced from starch or sugar rich plants such as sugarcane or maize for bioethanol or oil seed crops such as rape seed, soya bean, palm oil or jatropha for bio diesel [3]. Biofuel production is a highly contested topic with different driving forces and diverging interests. While the global North is pushing fuel production to get more climate friendly fuels and decrease its dependence on fossil fuels, the global South additionally sees it as a mean to promote rural development [4]. Biofuels in developing countries particularly Africa have potential to dramatically improve the environment, reduce dependency on fossils fuels and revitalise socio economic conditions of rural communities by providing employment opportunities and access to new markets.

Despite these compelling benefits, there is significant disagreement on the energy efficiency and net social, economic and environmental impact of 
biofuel systems. Several research studies have revealed that biofuels have a significant impact on food security for growing populations [5] with some attributing the 2008 world food prices hikes to biofuels [6, 7]. Particularly in the rural south, the expansion of biofuels has also been identified as a major driver of large scale transfer of valuable land resources from indigenous land users to commercial enterprises [8]. Biofuels have been found to have adverse effect on local ecological systems [9]. As such, environmental movement groups have mobilised against large scale biofuel production labelling them "land grabs" which are aimed at "replacing millions of hacters of local agricultural systems and rural communities working in them, with large mono crop plantation controlled by multinational corporations" [10].

\section{Biofuel Programmes in Zimbabwe}

Zimbabwe is a land locked country in Southern Africa and imports all of its fuel mostly through Mozambique, Botswana and South Africa and has for a long time been searching for sustainable energy supplies. One of the oldest ethanol plants on the continent is found in Zimbabwe's South Eastern lowveld and started operations in the 1960s and continued production after independence in 1980. The plant is run by Triangle Ltd. and produces approximately 120,000 litres of bioethanol daily and 40 million litres annually using a variety of feedstocks - different grades of molasses, cane juice or even raw sugarcane itself [11]. Another biofuel project, a multi-million dollar public private partnership between Green Fuel (PVT) Ltd. and state owned ARDA, was recently set up at the Chisumbanje estates in the same region and aims at manufacturing anhydrous ethanol from sugarcane to supply domestic and regional markets [12].

The government of Zimbabwe (GoZ) considers local fuel production strategic for curbing greenhouse gas emissions and saving on foreign currency [13].
Historically, unleaded 93 was the only petrol option on the fuel market. However, since October 2013, mandatory blending legislation was effected requiring blending of $5-15 \%(\mathrm{v} / \mathrm{v})$ ethanol and petrol, leaving consumers with no freedom to choose between blended or unleaded petrol. The regulations were gazetted as a way to stimulate and sustain the development and expansion of biofuel initiatives and stipulates that all procurers and wholesalers of unleaded fuel must only do so after ensuring it has been blended with a minimum $5 \%$ of ethanol (E5) up to $15 \%$ produced by a licenced producer [14].

Although some African governments such as those in Zimbabwe, South Africa and Mozambique have put significant efforts in developing the biofuel sector, government mandates and increased funding, do not necessarily mean a new product or technology will live up to its potential. Lack of public understanding and consumer perceptions could become one of the many barriers to biofuels in any economy [15]. To build such understanding, research is needed that investigates the level of awareness and prevailing attitudes of motorists towards ethanol blended fuel in countries at the fore front of biofuel promotion, such as Zimbabwe.

\section{Understanding Public Perceptions}

Regarding perceptions and attitudes towards biofuels, a number of surveys have been administered to fleet operators of public (government) and private (company) fleets in a number of states in the US and Europe. One such study was carried out in 6 European cities and one city in China to investigate fleet operators' attitudes towards bio-ethanol fuel and bio-ethanol vehicles (cars and buses) [16]. These studies have mainly been done in the context of the European Union (EU) energy strategy which contains set targets of replacing 5.75\% of all the fuel used for transportation by biofuels [17]. Given these expectations, much research to date has concentrated on the technical aspects of the supply 
side while much less literature is available on the demand side [18].

Research on adoption of biofuel technologies by smallholder farmers in Zimbabwe examines factors that promote and deter small scale farmers to adopt jatropha crop for the production of biofuels [19]. Her study focuses on the supply side of biofuels and neglects consumer perspective which is vital in the eventual adoption of renewable energy technologies. Research into the degree of biofuel acceptance by fuel consumers and its determinants may inform communication strategy to be used to the general public and in particular, to potential end users [18]. In addition, insights into consumer beliefs regarding biofuels are of interest as input to the present debate on the influence of biofuel production on rising food prices [19].

The main objective of this paper is to determine consumer perception, beliefs and knowledge regarding the use of biofuel as blended vehicle fuel.

\section{Materials and Methods}

Data on motorists' knowledge, attitudes and perception were collected using interviews, media sources and a consumer survey conducted in December 2013. Stratified random sampling procedures were used. Eight main fuel stations associated with different oil companies were randomly selected from various low, medium and high density suburbs and the central district of Zimbabwe's capital city, Harare. Questionnaires were distributed amongst people who fueled up their cars at these stations. Survey questionnaires were also administered by way of emails and direct interviews with motorists. A total of 200 questionnaires were administered and used for analysis.

The study adopted the knowledge, attitude, perception (KAP) survey model. KAP survey is a quantitative method that provides access to quantitative and qualitative information. KAP design was used because it allows, in a single survey, the collection of large amount of data that will be subject to statistical analysis.

The first part of the questionnaire; awareness and familiarity with alternative types of fuels was measured. Respondents' extent of knowledge on the various fuel types that were available on the market was measured using a 5-point Likert scale ranging from $1=$ very little knowledge to $5=$ excellent knowledge. Since information is important in determining consumer understanding of biofuel, respondents were also asked to state 3 main topics of interest on biofuels and the importance they attach to various information sources they use to obtain this information. The latter was again measured on 5-point Likert scale ( 1 = very unimportant, $5=$ very important).

To understand motorist's perceptions, in the second part of the questionnaire, respondents were asked whether they agreed or disagreed with a number of biofuel properties, such as environmental friendliness and whether bioethanol improves the energy effectiveness of the engine or not. They were also asked if they had experienced any performance related problems with their vehicle in the last month and if so, they were required to state the problem. There is a greater likelihood that favourable attitudes will translate to actual behaviour [20]. As such, motorists were asked to compare their attitude towards ethanol blended fuel before it was introduced and after their experience using it. They were also asked if they would recommend other motorists to drive ethanol powered cars.

In the last section, motorists were asked to comment on the prospects of biofuel developments, including stating the importance they attach to various factors that stand in the way of biofuel consumption in Zimbabwe. All the data were analyzed with statistical package for social sciences (SPSS) version 19.0. Frequency tables used and bivariate analyses such as cross tabulations; independent sample $t$-tests and one-way analysis of variance were used to analyse the data. 


\section{Results}

\subsection{Characteristics of the Survey Sample}

Table 1 provides an over view of the socio-demographic characteristics of the respondents. From the study sample of 200 motorists, the overwhelming majority $(71.5 \%)$ were male drivers and relatively younger group; $44.5 \%$ were between the ages of 18-30 followed by the 31-40 age group. Most of the respondents were highly educated with over $60 \%$ holding either an undergraduate or post-graduation qualification.

Regarding vehicle characteristics, the majority in the sample fell under the category of small family cars. Cars which were classified as small cars were those with an engine capacity of 2 litres or below. About one fifth of the sample comprised cars with 2-3 litre engine capacity were classified as medium size cars. An overwhelming number $(86 \%)$ of cars characterised as small and medium cars had private ownership and the drivers who took part in the survey were the original owners. Trucks, vans and buses comprised about $10 \%$ collectively, of the sample. These were mainly company owned vehicles used for different purposes such as transportation of employees to work, delivery of products and other services.

\subsection{Public Understanding of Blended Fuel}

The public media advertisements in Zimbabwe for blended fuel claim that there is no significant difference between unleaded petrol and petrol blended with 5 to $15 \%$ of ethanol. They acknowledge that $85 \%$ ethanol blend requires engine modification. ${ }^{1}$ To ascertain consumer reaction to this, respondents were first asked if there were aware of the availability of different types of fuel. In general, $93.5 \%$ of the sample population stated that they were aware of the various types of fuel that were available on the market. To understand further the levels of knowledge they had

\footnotetext{
${ }^{1}$ E.g. Article in NewZimbabwe.com.8 December 2013, Motorists warm to ethanol blending.
}

on these different types of fuel including ethanol blends, questions were put on a scale of 1-5 (1-very little knowledge and 5-excellent knowledge) and the results are summarised in Table 2.

Table 2 shows that motorists are having difficulty in distinguishing between ethanol blends that have been hastily introduced on the market although a significant number $(73.6 \%)$ maintain very good and excellent knowledge on unleaded petrol (gasoline not blended with ethanol). In addition, the majority of the consumers did know what the effects of blended fuel were on engine performance, where to get their engines modified to take a high ethanol blend, or what the cost of the modification would be.

One of the underlying assumptions why governments are quick to deploy biofuels onto the market is the assumption that the majority of the motor users actively seek information on new technologies and legislation from a wide range of sources. In order to examine this assumption, efforts put into acquiring information on ethanol blends were measured through the stated total time spent going through this information in the last 30 days. The results showed that the majority of the respondents (78.6\%) on average spend less than 2 hours in a month going through information on bio-ethanol.

In a group discussion with 7 male drivers who participated in the survey, the majority attributed their

Table 1 Socio-demographic characteristics of the respondents.

\begin{tabular}{ll}
\hline Gender & Frequency \\
\hline Male & $71.5 \%$ \\
Female & $28.5 \%$ \\
\hline Age & $44.5 \%$ \\
\hline $18-30$ & 34.5 \\
$31-40$ & 14.5 \\
$41-50$ & 6.5 \\
$51-60$ & \\
\hline Education & \\
\hline No education & 0 \\
Primary education & 1.0 \\
Secondary education & 29.5 \\
Undergraduate & 40.0 \\
Post graduate & 29.5 \\
\hline
\end{tabular}


Table 2 Level of knowledge of the various fuel types.

\begin{tabular}{llllll}
\hline $\begin{array}{l}\text { Level of knowledge about various types } \\
\text { of fuel and flexi-fuel technology }\end{array}$ & Unleaded \% & E5 (Blend) \% & E10 (Blend) \% & E85 (Blend) \% & $\begin{array}{l}\text { Flexi-fuel } \\
\text { Technology \% }\end{array}$ \\
\hline Very little knowledge & 5.2 & 32.9 & 13.3 & 16.5 & 26.9 \\
Little knowledge & 2.1 & 17.1 & 7.4 & 35.8 & 24.0 \\
Average knowledge & 19.2 & 20.1 & 40.7 & 16.5 & 17.7 \\
Very good knowledge & 48.2 & 16.5 & 19.6 & 17.0 & 16.0 \\
Excellent knowledge & 25.4 & 13.4 & 19.0 & 14.2 & 15.4 \\
\hline Table 3 Level of importance of information sources. & & & & Very \\
\hline Level of importance of & Very & Rather & Neither & Rather & important \\
sources of information & unimportant & unimportant & inimportant or & important & 68.7 \\
\hline Newspapers & 5.6 & 2.6 & 2.1 & 21.0 & 66.1 \\
Fuel stations & 5.8 & 2.1 & 3.2 & 22.8 & 53.3 \\
Radio & 5.6 & 5.0 & 12.2 & 23.9 & 50.0 \\
TV & 5.7 & 4.6 & 12.6 & 27.0 & 50.0 \\
Family/friends & 5.7 & 5.0 & 10.7 & 28.6 & 46.6 \\
Internet & 12.2 & 9.5 & 6.1 & 25.7 & 22.9 \\
Organisation notice boards & 21.4 & 9.2 & 10.7 & 35.9 & 19.2 \\
Brochures/flyers & 12.8 & 5.1 & 23.1 & 39.7 & .0 \\
Other (car parks, journals, posters, & 58.3 & 8.3 & 16.7 & & 16.7 \\
vehicle service providers) & & & & &
\end{tabular}

lack of adequate knowledge including efforts they put into acquiring information on bio-ethanol, to a lack of availability of information in various media outlets. This reflects a general lack of information dissemination efforts put into biofuels in Zimbabwe in various media outlets that are accessible to the majority of ethanol users.

To understand the potential of various channels of information dissemination, respondents were asked to state the level of importance they attach to different types of sources of information on a scale of 1-5 (1 very unimportant and 5 very important). The results are presented in detail in Table 3.

The results tabulated (Table 3) show that respondents attach more importance to mass media sources such as newspapers (68.7), fuel stations (66.1\%), radio $(53.5 \%)$ and TV $(50 \%)$, than journals, flyers etc. which was stated as unimportant (58.3\%). Family and friends were also stated as significant preferred choice $(50 \%)$.

The main topics which were highly sought on biofuels are prices of bio ethanol (20.2\%), biofuel production $(16.1 \%)$ followed by technology of ethanol vehicles $(12.7 \%)$ (data not shown). Focus group discussions revealed that in all these three aspects, motorists felt they were not properly consulted and advised before mandatory blending was introduced. One motorist explained:

"The problem with the wholesale introduction of ethanol blended fuel is that it is being forced down our throats. I imported my car from Japan and it is clearly marked 'use unleaded petrol only' but I am forced to take ethanol blends here. The government's decision to ban unleaded petrol from the market has exterminated our freedom to choose. I do not see any benefits for the motorist from such a winner-take-all mandatory policy.

With regards to information on pricing, the majority of motorists disagreed significantly with ethanol advertising, particularly with one particular advertisement which claimed that blended fuel gave "more distance for your dollar" [12].

Their perception was that ethanol blending actually comes with an extra cost burden on the consumer. 
This is reflected from information gathered from one particular motorist who reported that he used to spend $\$ 60$ on a full tank of 40 litres unleaded petrol which would take him for $520 \mathrm{~km}$, but with the same full tank of E10 he now travels $400 \mathrm{~km}$. Althought the price of E10 has gone down by $\$ 0.02$, this motorist now requires $\$ 76,96$ to maintain the same level of travel. Although the final costs of ethanol blends are country specific, in general scientific findings back the idea that ethanol blends contains less energy per litre compared to unleaded [21].

\subsection{Motorists Understanding of Bioethanol}

Characteristics

In order to understand motorists' perception of ethanol blended vehicle fuel, they were asked to state their level of agreement and disagreement with a number of statements regarding bioethanol properties. The results are shown in Table 4.

The majority of respondents agreed with the statements about with the safety aspects of ethanol and the source of ethanol (feedstock). But they seemed unsure about the technical attributes of ethanol such as whether it improves energy effectiveness of engine or not. Many experimental studies have confirmed that ethanol in gasoline engines increases engine (energy) efficiency, torque, and power compared to baseline gasoline tests, mainly because of a superior fuel octane rating [21].

The majority disagreed with the environmental attributes of ethanol such as being cleaner than gasoline. Although some scientific studies have shown that tailpipe emissions from vehicles running on ethanol fuels are generally cleaner than those from gasoline, evaporative emissions have been noted to be generally higher for ethanol, especially in low-percentage blends [22]. Information gathered from interviews with some of the respondents suggests that disagreement with official claims about ethanol being environmentally friendly could be a result of popular hostility towards government policy in general.

Judging from political representation, Harare residents actively participate in opposition politics. Reservations expressed about ethanol blended fuel reflect scepticism by Harare motorists who view all government initiatives with suspicion. One Harare motorist went all the way to the constitutional court challenging ethanol blending ratios and the governments' decision to award one private company, Green Fuels with the rights to produce ethanol used for mandatory blending. In his submissions, the complainant argues:

"Mandatory blending is a violation of the people's fundamental right as provided in the Bill of Rights contained in Chapter 4, Article 47 of the new Constitution: freedom of choice and of fairness. The preamble of the Constitution speaks of the right of the resolution to build a just and prosperous nation founded on the values of freedom and fairness among others. The monolithic right granted to Green fuels to be a sole supply of ethanol is completely unconstitutional. Surely, other licensed traders and blenders ought to be allowed to purchase from Triangle (Pvt) Ltd or other such companies. The actions by the state showed contempt of Zimbabweans as the regulations to migrate from E5 up to E20 have been done without any

Table 4 Perceptions on bio ethanol properties.

\begin{tabular}{|c|c|c|c|c|}
\hline Perceptions on bio-fuel properties & $\begin{array}{l}\text { Disagree } \\
(\%)\end{array}$ & $\begin{array}{l}\text { Unsure } \\
(\%)\end{array}$ & $\begin{array}{l}\text { Agree } \\
(\%)\end{array}$ & $\begin{array}{l}\text { Total } \\
(\%)\end{array}$ \\
\hline $\begin{array}{l}\text { Bio-ethanol burns cleaner than gasoline and does not } \\
\text { contribute to the emissions of greenhouse gases }\end{array}$ & 48 & 18 & 34 & 100.0 \\
\hline $\begin{array}{l}\text { Bio-ethanol can be produced from starch, sugarcane and a } \\
\text { variety of feedstock }\end{array}$ & 12 & 16 & 72 & 100.0 \\
\hline Bio-ethanol can harm the environment if it leaks out & 14 & 22.6 & 63.4 & 100.0 \\
\hline Bio-ethanol can improve the energy effectiveness of the engine & 15.5 & 60.1 & 24.4 & 100.0 \\
\hline
\end{tabular}


scientific research by an independent authority to study the effects of ethanol on vehicles. There is no explanation for this accelerated movement and in the absence of such; the inescapable conclusion is that the whole motive is that of profit and greed" [23].

\subsection{Experience and Evaluation of Ethanol Blended Fuel}

The study also examined how motorists' experience has been since they started to drive on ethanol fuelled vehicles. The results indicate that in general it was not very bad with half the population sample indicating it was either good or very good as illustrated in Fig. 1.

From the survey findings, new drivers are the ones who seem to have a bad experience compared to seasoned drivers.
To understand further motorists experience and evaluation of ethanol blended fuel, respondents were asked to state if they had experienced any problem and of what nature. The results show that $38.5 \%$ had never experienced any performance related problem while a significant number cited problems ranging from poor idling (36\%), lack of power $(19.5 \%)$ and difficulty with engine starting (16.5\%) as shown in Table 5.

A local franchise dealing with Nissan models, Nissan Zimbabwe has warned of potential technical related problems that will arise from ethanol blends and stated that the use of ethanol blends higher than $10 \%$ renders all Nissan product fuel systems unwarrantable. In March 2014, a motorist approached the courts challenging government's mandatory fuel blending

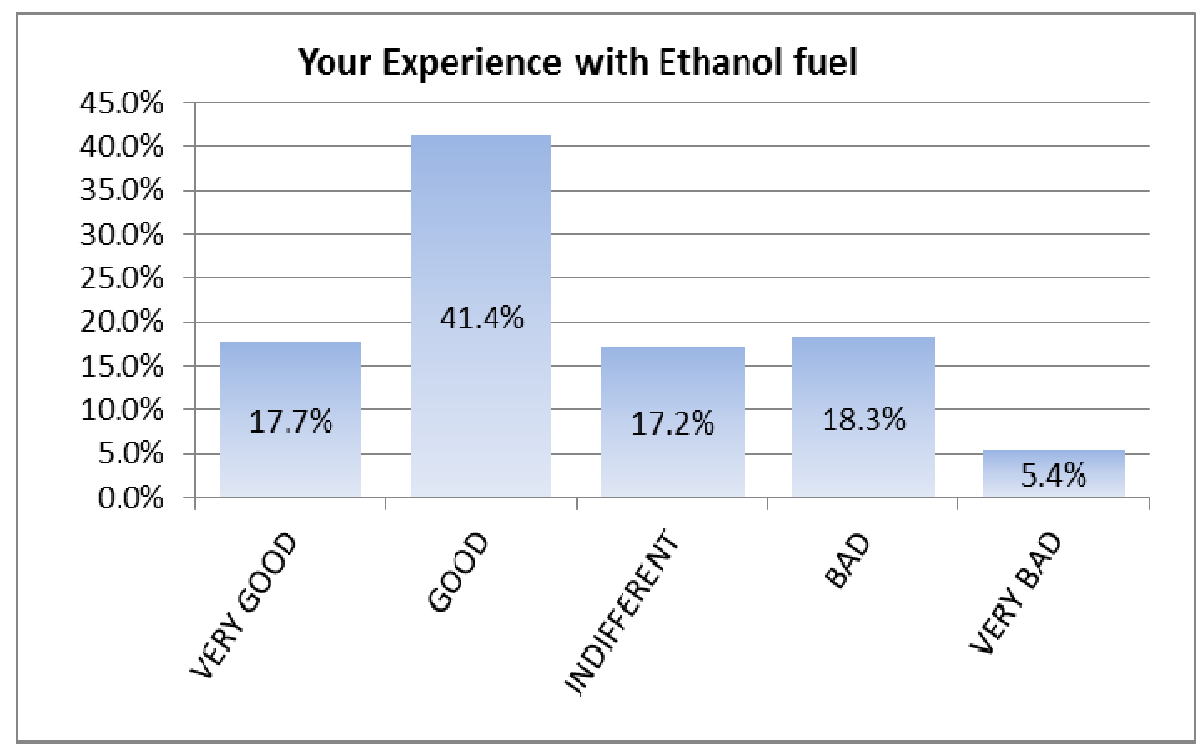

Fig. 1 Experience with ethanol blended fuel.

Table 5 Vehicle performance with blended fuel.

\begin{tabular}{ll}
\hline Experienced any performance related problems & Percent \% \\
\hline No problem & 38.5 \\
Hard to start & 16.5 \\
Stalled after starting & 3.0 \\
Stalled in traffic & 8.0 \\
Poor idle & 36.0 \\
Hesitation & 6.0 \\
Lack of power & 19.5 \\
Check engine light & 6.0 \\
Other & 3.0 \\
\hline
\end{tabular}


policy claiming to have spent over $\$ 2,000$ after his car developed a fuel-related mechanical problem after using E10 fuel blend. The complainant argued in his founding affidavit that his Mitsubishi Pajero developed fuel injection complications after he ran it on E10 fuel blend, forcing him to replace the system at a cost of $\$ 2,232$. He argued that his vehicle cannot therefore operate on fuel mixed with ethanol and the high court should issue an order declaring the mandatory blending of ethanol with unleaded petrol unconstitutional, because the policy violated his right to acquire, hold and occupy property [24].

\subsection{Motorists'Attitudes towards Ethanol Blended Fuel}

To elicit information on current attitudes which motorists have towards ethanol blended fuel, respondents were asked whether they felt more or less well disposed to ethanol blends at the time of the survey than they had when the new fuel dispensation was introduced three months earlier.

These results were cross tabulated with drivers' age and the types of cars they drove, showing that the majority $(46 \%)$ of the respondents who evaluated blended fuel positively had three or more years of driving experience and were generally aged between
41 and 60. This group is pragmatic drivers who hold a utilitarian view of cars; the vehicles they used were generally produced before the year 2000. The 35\% who evaluated ethanol blends negatively were generally young, educated and aspiring middle class drivers who believed that ethanol blending diminished engine performance in their newer cars (Fig. 2).

\subsection{Future Prospects of Blended Fuels}

To measure the extent to which current attitudes will influence further market penetration of biofuels, respondents were asked whether they would recommend others to use ethanol (Fig. 3). This is important in anticipating and planning on how to manage significant swings in public attitudes on ethanol in order to ensure sustainable utilisation. Fig. 3 suggests that the majority are still not $100 \%$ sure if they would recommend although a combined $60.1 \%$ indicated that they would recommend others to use ethanol as depicted in Fig. 3.

What drives new motorists to adopt new technologies such as the adoption of flexi fuel upgrade kits in order to use E85? Firstly the survey established that 24.2 were using E85 fuel against $75.8 \%$ who were using other lower blends of ethanol fuel. The primary

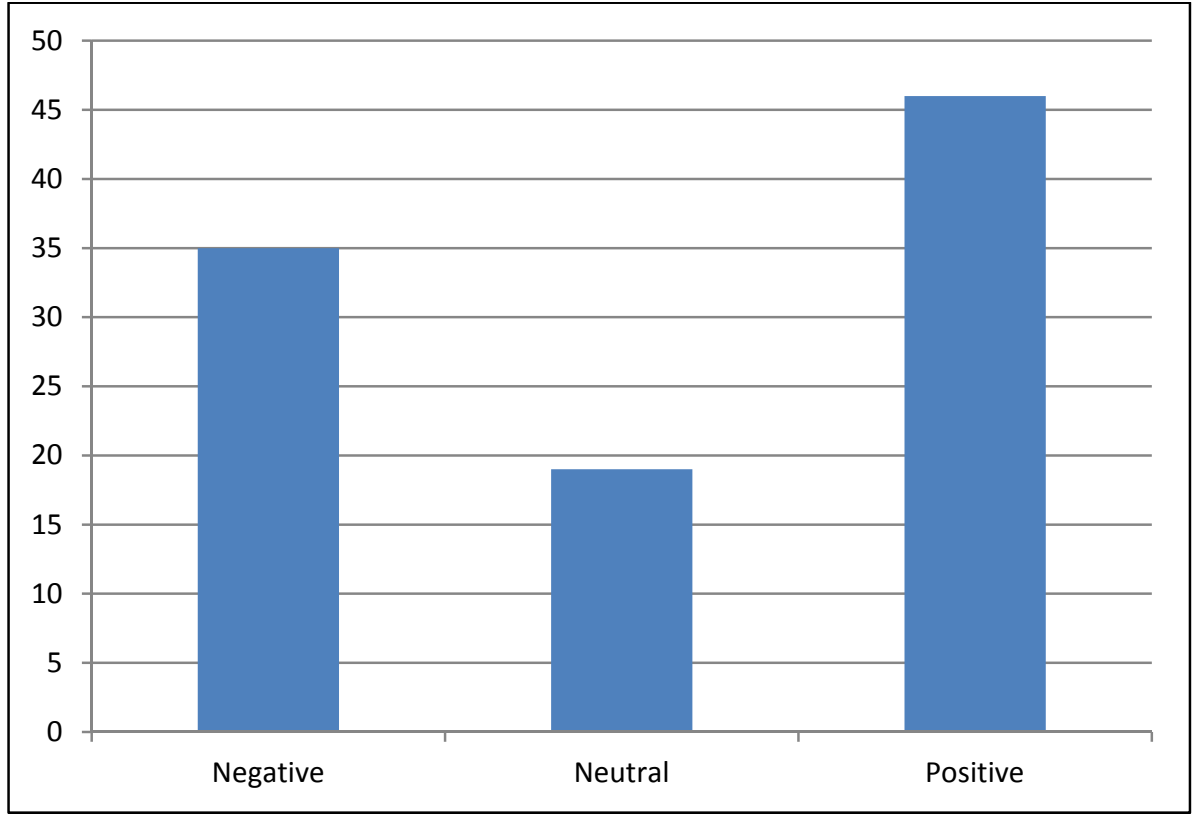

Fig. 2 Motorist's attitude towards ethanol blended fuel. 


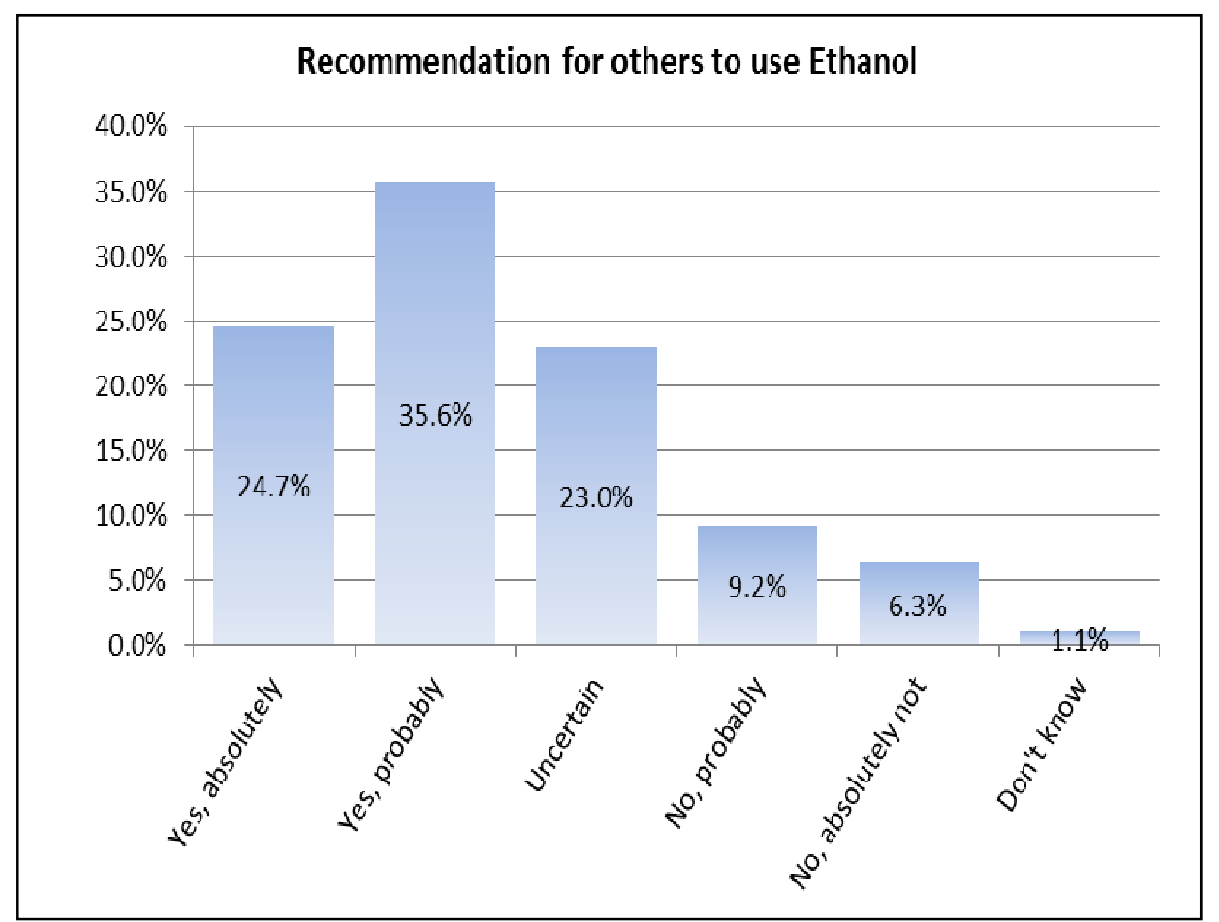

Fig. 3 Recommendation for others to use ethanol blends.

reason that motivates most motorists to adopt E85 is not the need to support the production and development of ethanol fuel per se, but the anticipated net economic benefits of purchasing fuel which was priced marginally lower than other blends. Most drivers who had modified their engines to take E85 had smaller cars and could be classified as "city drivers" and these were largely cab drivers. Interestingly environmental issues were stated as of least concern in choosing E85 as a preferred choice of fuel.

To gauge opportunities and constraints towards biofuel production and utilisation, motorists were also presented with a list of factors which were grouped in 5 different categories: policy and market, fuel, vehicles, infrastructure and feedstock production. The importance of the different barriers was indicated by giving a score on the Likert scale to the barriers stated. The distribution between the relevance of the different barriers categories was not very significant. All the five barrier categories were seen as relevant barriers that are hindering biofuel production and consumption as their average score rating was between 3 and 4, but policy and marketing category ranked highest towards the most important barrier with an average score of 3.8 whilst feedstock category was ranked the least with an average score of 3.3.

Looking at the most important barrier category policy and market, on the Likert scale from 1 to 5 , lack of customer awareness and market acceptance and lack of readily available information, had an average score of 4.1. This average score indicates that these two barriers are the most important among all possible barriers. The other two barriers lack of harmonisation in policy and among Government agencies and lack of experience on the market were ranked between 3 and 4 as they both had an average score of 3.9.

In the Vehicle category respondents indicated vehicle compatibility issues as the most important factor hindering biofuel production and consumption with an average score of 3.9 as well. In the Infrastructure category insufficient bio-fuel production capacity was rated as a relevant barrier with an average score of 3.6. Lack of sufficient feedstock for the biofuel production units was seen as a relevant barrier with an average score of 3.5 in the feedstock category. 


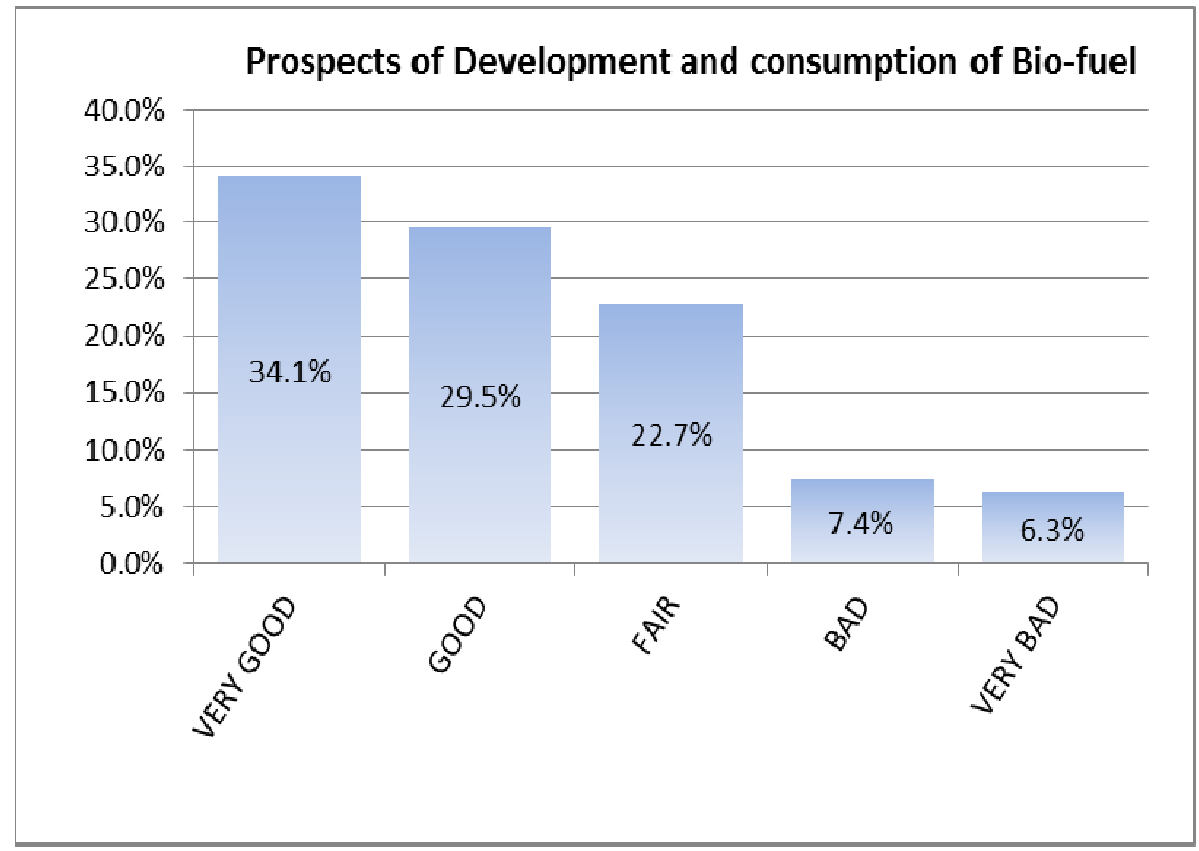

Fig. 4 Future prospects.

To understand the future trajectories of ethanol use, respondents were asked to comment, in their own opinion how they rate the future of biofuel developments and utilisation. A large number seemed positive about the future of biofuels, $34.1 \%$ reported it was very good, $29.5 \%$ good while only $6.3 \%$ felt it was very bad as reflected in Fig. 4.

\section{Discussion and Conclusion}

In general, awareness of ethanol blended fuel was moderate but knowledge amongst respondents on the technical and environmental attributes of bio-ethanol was low. Although some respondents such as older drivers evaluated biofuels positively, some motorists maintain that ethanol blends damage car engines. Another obstacle towards the adoption of biofuels is the fact that a substantial group of respondents believe that biofuels can only be used in modified engines. Furthermore, most consumers are unaware of the positive influence of blended biofuels on engines. Although the Zimbabwean public authorities emphasize the possibilities and advantages for the local economy, consumers either do not have explicit opinions or are largely unaware of biofuel characteristics. The main adoption hurdles will be price and availability at fuel stations, since these two characteristics are very important for fuel users with biofuels not meeting these requirements at the present time.

In order to transform the current fossil fuel based economy in Zimbabwe into a low carbon, a comprehensive institutional, legal and policy framework that supports biofuel production and utilisation should be put in place. The absence of such a framework and site specific sustainability analysis that engenders feedstock production has been identified as a key missing link in Zimbabwe's biofuel programme [25]. In light of this study, an institutional, policy and legal framework should support consumer education through massive awareness campaigns for bioethanol to dispel negative perceptions associated with ethanol blends. More importantly, there is need to improve citizen's understanding of and participation in biofuel policy and encourage public critical analysis of ethanol blends in general.

Furthermore research and development efforts should be invested in determining the use of other feedstock such as sweet sorghum in the production of 
different grades of ethanol. The government should also aim at catalysing and sustaining biofuel investments through providing incentives such as credit guarantees and low interest loans for setting up biofuel production. The state should play a meaningful role such as regulating the prices of fuel in order to give ethanol a competitive advantage. Most motorists from our survey expect a significant reduction in the prices of fuel as a result of ethanol blending. In other countries where ethanol blends scored significant success, such as in Brazil, ethanol was promoted under a marketing programme with a slogan "let's unite, make alcohol" [26]. Such an initiative, together with promoting the importation of flexi fuel cars will go a long way in swaying public opinion in favour of ethanol blended fuel.

The scientific value of this study is that, it exposes barriers to effective implementation of green initiatives by focusing on some of the factors that could lead to consumer passivity in markets where ethanol blended fuels have been introduced. Based on the data from this study, the paper stresses the need to consider the socio political context before the introduction of ethanol blends. A participatory and sustainability analysis framework that addresses pricing issues and scientific inquiry that anticipates possible effects of ethanol blends and design possible remedies, is likely to create a fertile context in which consumers take a greater interest and recognise the benefits of biofuel consumption.

This paper provides a base on which future research can be done. Further studies of this type, with larger and representative consumer samples in other areas of Zimbabwe or different countries, would be beneficial to compare different biofuel policies and the accompanying biofuel beliefs. The study can also extend to include consumers who buy blended fuel not for use in vehicles by for industrial or domestic use in generators. Longitudinal studies involving not only motorists and the general public but a segment of the younger generation may provide important insights for future trajectories of renewable energy and energy policies.

\section{Acknowledgements}

This publication was made possible by support from the Social Science Research Council's Next Generation Social Sciences in Africa Fellowship, with funds provided by Carnegie Corporation of New York. We are also grateful to Rachel Makasi and Carolina Milhorance deCastro for commenting on earlier drafts.

\section{References}

[1] Davison, S. C. 2011. "Liquid Biofuels Strategies and Policies in Selected African Countries: A Review of Some of the Challenges, Activities and Policy Options for Liquid Biofuels." Working Paper Prepared for PISCES by Practical Action Regional Office for Eastern Africa in collaboration with Pipal Ltd. June 2011.

[2] Delshad, A. B., Raymond, L., Sawicki, V., and Wegener, D. T. 2010. "Public Attitudes towards Political and Technological Options for Biofuels." Energy Policy 38 (7): 3414-25

[3] Molony, T., and Smith, J. 2010. Briefing Biofuels, Food Security, and Africa. African Affairs, 109-436, 489-98.

[4] Gmunder, P. 2010. "Current and Future Challenges of Biofuel Production in Developing Countries." In Future Perspectives of 2nd Generation Biofuels. TA-Swiss. Zürich: vdf isbn:978-3-7281-3334-2.

[5] FAO. 2008. The State of Food and Agriculture 2008. Biofuels: Prospects, Risks and Opportunities. Rome: Food and Agriculture Organization.

[6] Mitchell, D. 2008. A Note of Rising Food Prices (Policy Research Working Paper 4682). The World Bank, Washington DC.

[7] Oxfam. 2008. "Another Inconvenient Truth: How Biofuel Policies Are Deepening Poverty and Accelerating Climate Change." Briefing Paper 114, Oxford: Oxfam International

[8] Anseeuw, W., Wily, A. L., Cotula, L., and Taylor, M. 2012. Land Rights and the Rush for Land: Findings of the Global Commercial Pressures on Land Research Project, ILC, Rome.

[9] Vermeulen, S., and Cotula, L. 2010. "Over the Heads of Local People: Consultation, Consent, and Recompense in Large-scale Land Deals for Biofuels Projects in Africa." The Journal of Peasant Studies 37 (4): 899-916. doi: 10.1080/03066150.2010.512463.

[10] GRAIN. 2008. Stop the Agrofuel Craze! GRAIN L $\begin{array}{lllll}\text { Seeding } & \text { L. } & 19 & \text { May } & 2008\end{array}$ 
http://www.grain.org/seedling/?id=477.

[11] Amigun, B., Musango J. K., and Stafford, W. 2011. "Biofuels and Sustainability in Africa." Renewable and Sustainable Energy Reviews 15 (2): 1360-72.

[12] Green Fuel. 2013. Green Fuel: Driving the Future. Available: http://www.greenfuel.co.zw/ (2013, December 17).

[13] Government of Zimbabwe. 2012, Zimbabwe Energy Policy, Ministry of Energy and Power Development.

[14] Government of Zimbabwe. 2013. Statutory instrument number 17 Petroleum (mandatory blending of anhydrous ethanol with unleaded petrol) Regulations 2013. Zimbabwe Energy Regulatory Authority

[15] Cacciatore, M. A., Binder, A. R., Scheufele, D. A., and Shaw, B. R. 2012. "Public Attitudes toward Biofuels: Effects of Knowledge, Political Partisanship and Media Use." Politics and the Life Sciences 31 (1-2).

[16] Landahl, G. 2009. Report on Driver Attitudes towards Flexi Fuel Vehicles Bio-Ethanol for Sustainable Transport Project. TREN/05/FP6EN/S07.53807/019854.

[17] European Commission. 2006. Fuelling Our Future: The European Commission Sets out Its Vision for an Energy Strategy for Europe, IP/06/282, Press release, Brussels, 8 March 2006.

[18] Van de Velde, L., Verbeke, W., Popp, M., Buysse, J., and Hullenbroeck, G. V. 2009. "Perceived Importance of Fuel Characteristics and Its Match with Consumer Beliefs about Fuels in Belgium.” Energy Policy 37 (8): 3183-93. doi: 10.1016/j.enpol.2009.04.022.

[19] Nyamwena-Mukonza, C. 2012. "Adoption of Biofuel Technologies by Smallholder Farmers in Zimbabwe." Paper presented at the 8th PhD GLOBELICS Academy in Brazil www.redesist.ie.ufrj.br/ga2012/paper/ChipoMukonza.pdf.

[20] Larsen, V., Johansen, T., and Schramm, J. 2009. "Ethanol as a Fuel for Road Transport." Technical University of Denmark.

[21] Jeuland, N. 2004. "Potentiality of Ethanol as a Fuel for Dedicated Engine' Oil and Gas Science and Technology."

[22] Mushava, E. 2013. Petrol Blending Challenged in Court. Newsday: Harare.

[23] Nleya, F. 2014 Motorist Takes Minister to Court. Newsday: Harare.

[24] Sandalow, D. 2006. Ethanol: Lessons from Brazil. The Brookings Institution.

[25] Moyo, P., Moyo, M., Dube, D., and Rusinga, O. 2014. "Biofuel Policy as a Key Driver for Sustainable Development in the Biofuel Sector: The Missing Ingredient in Zimbabwe's Biofuel Pursuit." Modern Applied Science 8 (1). ISSN 1913-1844 E-ISSN 1913-1852.

[26] Duvenage, I., Langston, C., Stringer L, C., and Dunstan, K. 2013. "Grappling with Biofuels in Zimbabwe: Depriving or Sustaining Societal and Environmental Integrity?" Journal of Cleaner Production 42: 132-40. doi: 10.1016/j.jclepro.2012.11.011. 